\title{
PERSEPSI WARGA SEKOLAH TENTANG PROGRAM PERCEPATAN BELAJAR DI SMP PANGUDI LUHUR DOMENICO SAVIO SEMARANG
}

\author{
Albertus Suwarto, Ishartiwi \\ SMP Pangudi Luhur, Universitas Negeri Yogyakarta \\ albertsuwarto@gmail.com, ishartiwi@uny.ac.id
}

\begin{abstract}
Abstrak
Penelitian ini bertujuan untuk mengetahui pelaksanaan PPB di SMP Pangudi Luhur Domenico Savio Semarang tahun pelajaran 2010/2011 dilihat dari: 1) konteks pelaksanaan PPB, 2) input program PPB, 3) proses pelaksanaan program pembelajaran PPB, dan 4) output program. Pengambilan data dilakukan dengan kuesioner, dokumentasi, wawancara dan observasi untuk data kualitatif. Analisis data dilakukan secara deskriptif. Hasil penelitian menunjukkan: pertama, konteks pelaksanaan PPB menunjukkan hasil tinggi 62,8\%. Pelaksanaan PBB dari sisi konteks dapat dilaksanakan dengan baik. Kedua, input program menunjukkan hasil tinggi, 85,2\%. Pelaksanaan PBB dari sisi input dapat dilaksanakan dengan baik. Ketiga, proses pelaksanaan program menunjukkan hasil tinggi, 79,7\% berarti pelaksanaan PBB dari sisi proses dilaksanakan dengan baik. Keempat, produk pelaksanaan program yaitu: (a) ujian/test formatif, (b) ujian/test semester, (c) ujian nasional dan (d) prestasi kegiatan ekstrakurikuler menunjukkan hasil tinggi,74,1\%. Hal ini berarti pelaksanaan PBB dari sisi produk dikatakan baik.
\end{abstract}

Kata kunci : persepsi, program percepatan belajar, cipp 


\section{Pendahuluan}

Program Percepatan Belajar (PPB) memberikan kesempatan bagi peserta didik untuk belajar sesuai kecepatan belajar masing-masing. Program ini diperuntukkan bagi peserta didik yang cerdas istimewa. Diharapkan PPB ini dapat memenuhi kebutuhan layanan pendidikan yang berbeda bagi mereka yang tergolong gifted. Selama ini PPB diselenggarakan di sekolahsekolah formal di berbagai jenjang pendidikan.

Pelaksanaan pembelajaran bagi anak cerdas istimewa mengacu kepada tujuan umum PPB (Depdiknas, 2007), yaitu: (1) memberikan kesempatan kepada PDCI/BI untuk mengikuti program pendidikan sesuai dengan potensi kecerdasan yang dimiliki, (2) meningkatan efisiensi dan efektivitas proses pembelajaran bagi PDCI/BI, (3) memenuhi hak asasi PDCI/ BI sesuai dengan kebutuhan pendidikan bagi dirinya, (4) membentuk manusia berkualitas yang memiliki kecerdasan spiritual, emosional, sosial, dan intelektual serta memiliki ketahanan dan kebugaran sosial, (5) membentuk manusia berkualitas yang kompeten dalam pengetahuan dan seni, berkeahlian dan berketerampilan, menjadi anggota masyarakat yang bertanggung jawab, serta mempersiapkan peserta didik mengikuti pendidikan lebih lanjut dalam rangka mewujudkan tujuan pendidikan nasional. PPB di SMP Pangudi Luhur Dominico Savio Semarang sudah berlangsung selama 11 tahun, setiap tahun ajaran diikuti paling banyak 20 siswa.

Persepsi warga sekolah sangat penting guna mendapatkan gambaran tentang pelaksanaan PPB. Persepsi merupakan suatu penafsiran yang terhadap situasi, dan bukannya suatu pencatatan yang benar terhadap situasi seperti dikatakan Krech (Thoha, 2000, p.124). Persepsi manusia terhadap seseorang, objek atau kejadian dan reaksi mereka berdasarkan pengalaman dan pembelajaran masa lalu. Persepsi bersifat evaluatif yaitu orang menafsirkan seberapa dekat persepsinya dengan realitas yang sebenarnya (Mulyana, 2000. p.75)
Agar pelaksanaan PPB dapat digambarkan dengan sistematis dan terukur, penelitian ini menggali persepsi warga sekolah tentang PPB dilihat dari setiap aspek program, yaitu context, input, process, and product dalam pelaksanaan PPB di SMP Pangudi Luhur Domenico Savio Semarang. Aspek input dibatasi pada karakteristik siswa, kompetensi guru, kurikulum dan sarana prasarana, aspek proses dibatasi pada proses pembelajaran dan pengelolaan administrasi pembelajaran, aspek konteks dibatasi pada masalah dukungan pemerintah, masyarakat, penyelenggara sekolah. Aspek output dibatasi pada prestasi akademis dan nonakademis.

Penelitian ini bertujuan untuk mengetahui: 1) persepsi warga sekolah terhadap dukungan pemerintah, masyarakat, dan penyelenggara sekolah; 2) persepsi warga sekolah terhadap karakteristik siswa, kompetensi guru, kurikulum dan sarana prasarana PPB; 3) persepsi warga sekolah terhadap proses pembelajaran dan pengelolaan administrasi pembelajaran PPB; 4) persepsi warga sekolah terhadap prestasi akademis dan non akademis PPB.

\section{Metode Penelitian}

Jenis penelitian

Jenis penelitian yang digunakan yaitu jenis penelitian deskriptif dengan tujuan untuk menggambarkan pelaksanaan program dilihat dari komponen Context, Input, Process, dan Product (CIPP).

Waktu dan tempat penelitian

Penelitian dilakukan selama 15 bulan terhitung sejak prapenelitian sampai dengan penelitian yaitu Februari 2010 sampai dengan April 2011. Penelitian ini dilakukan di SMP Pangudi Luhur Domenico Savio Kota Semarang yang beralamat di Jl. Dr. Sutomo No. 4 Kota Semarang, Jawa Tengah.

Populasi dan Sampel Penelitian

Populasi adalah seluruh warga sekolah di SMP Pangudi Luhur Domenico Savio. Sampel penelitian terdiri dari pe- 
ngurus harian yayasan 6 (enam) orang, pengurus Komite Sekolah 5 (lima) orang, siswa PPB sebanyak 29 siswa, orang tua siswa PPB sebanyak 29 (dua puluh sembilan) orang, Kepala Sekolah 1 orang, Ketua Program PPB 1 orang, dan guru PPB 22 orang. Jumlah total responden 93 orang.

Data, Intrumen, dan Teknik Pengumpulan Data

Data yang dibutuhkan yaitu data tentang: 1) Konteks (context) dengan indikator adalah (a) dukungan pemerintah, (b) dukungan pengurus yayasan, (c) dukungan masyarakat, dan (d) komitmen pengelola tentang pengembangan mutu pendidikan.

2) Input (input) dengan indikator : (a) karakteristik siswa PPB, (b) karakteristik guru PPB, (c) karakteristik kurikulum PPB, dan (d) ketersediaan sarana-prasarana pendidikan.

3) proses (process) dengan indikator: (a) administrasi kegiatan belajar mengajar (KBM) PPB, dan (b) kegiatan belajar mengajar (KBM). 4) pascapelaksanaan (product) dengan indikator: (a) test/ujian formatif, (b) test/ujian formatif semester, (c) Ujian Nasional, dan (d) prestasi kegiatan ekstrakurikuler
Instrumen yang digunakan mengumpulkan data yaitu berupa kuesioner, dokumentasi, observasi dan pedoman wawancara. Data dikumpulkan dengan cara membagi kuesioner kepada 93 sampel penelitian, mewawancarai pengelola PPB dan guru serta mempelajari dokumen PPB di SMP Pangudi Luhur Domenico Savio.

\section{Teknik Analisis Data}

Analisis data kuantitatif dari angket dilakukan dengan analisis deskriptif dalam bentuk kategori. Analisis dilakukan untuk menggambarkan konteks, input, proses dan produk. Analisis data yang didapat dari hasil wawancara, observasi dan dokumentasi dianalisis secara kualitatif deskriptif melalui tahapan reduksi data, penyajian data dan penarikan kesimpulan atau verifikasi (Huberman dan Miles (1992, p.23).

\section{Hasil Penelitian dan Pembahasan}

Deskripsi data konteks yang akan diuraikan meliputi deskripsi konteks secara keseluruhan dan deskripsi indikatorindikator konteks. Data diperoleh dari 43 responden penelitian, dengan hasil sebagai berikut:

Tabel 1. Konteks PPB

\begin{tabular}{ccccc}
\hline No & Rentang Skor & Kategori & Frekuensi & Persentase \\
\hline 1 & $4,0 \leq$ Skor & Sangat Tinggi & 10 & $23,3 \%$ \\
2 & $3,3 \leq$ Skor $<4,0$ & Tinggi & 17 & $39,5 \%$ \\
3 & $2,7 \leq$ Skor $<3,3$ & Sedang & 13 & $30,2 \%$ \\
4 & $2,0 \leq$ Skor $<2,7$ & Rendah & 1 & $2,3 \%$ \\
5 & Skor $\leq 2,0$ & Sangat Rendah & 2 & $4,7 \%$ \\
\hline \multicolumn{2}{r}{ Jumlah } & & 43 & $100 \%$ \\
\hline
\end{tabular}

Sumber : hasil penelitian, diolah $2011(\mathrm{~N}=43)$

Dari Tabel 1 tersebut diketahui bahwa skor konteks secara keseluruhan menunjukkan hasil sangat tinggi $(23,3 \%)$, tinggi $(39,5 \%)$, sedang $(30,2 \%$, rendah $(2,3 \%)$ dan sangat rendah $(4,7 \%)$. Hasil tersebut menunjukkan bahwa Konteks secara keseluruhan mayoritas memberikan penilaian termasuk kategori tinggi dan sangat tinggi (62,8\%). Hal ini berarti bahwa pelaksanaan PBB di SMP Pangudi Luhur Domenico Savio Semarang dari sisi konteks secara keseluruhan telah dapat dilaksanakan dengan baik.

Termasuk dalam konteks yaitu dukungan dari pemerintah, pengurus yayasan dan masyarakat serta komitmen dari 
pengelolanya. Secara faktual dukungan pemerintah yang dominan secara khusus lebih berupa legalitas formal perangkat peraturan dan perundang-undangan yang menjadi dasar penyelenggaraan PPB di seluruh Indonesia. Bagi SMP Pagudi Luhur Domenico Savio Semarang legalitas yang diperoleh melalui penunjukan oleh Pemerintah melalui Dinas Pendidikan Kota Semarang pada tahun 2001 dan baru pada tahun 2002 program itu terlaksana. Hal itu disebabkan oleh perlunya persiapan yang cukup seperti persiapan tempat belajar, guru, kurikulum, pengelola, dan sebagainya untuk mengubah sistem belajar 3 tahun di SMP menjadi hanya 2 tahun bagi siswa yang berkemampuan atau berbakat akademik istimewa.

Data input secara keseluruhan yang diperoleh dari 54 responden penelitian, diperolah hasil sebagai berikut:

Tabel 2. Input PPB

\begin{tabular}{|c|c|c|c|c|}
\hline No & Rentang Skor & Kategori & Frekuensi & Persentase \\
\hline 1 & $4,0 \leq$ Skor & Sangat Tinggi & 9 & $16,7 \%$ \\
\hline 2 & $3,3 \leq$ Skor $<4,0$ & Tinggi & 37 & $68,5 \%$ \\
\hline 3 & $2,7 \leq$ Skor $<3,3$ & Sedang & 7 & $13,0 \%$ \\
\hline 4 & $2,0 \leq$ Skor $<2,7$ & Rendah & 1 & $1,9 \%$ \\
\hline 5 & Skor $\leq 2,0$ & Sangat Rendah & 0 & $0 \%$ \\
\hline \multicolumn{3}{|c|}{ Jumlah } & 54 & $100 \%$ \\
\hline
\end{tabular}

Sumber : hasil penelitian, diolah $2011(\mathrm{~N}=54)$

Dari Tabel 2 tersebut diketahui bahwa skor input secara keseluruhan menunjukkan hasil sangat tinggi $(16,7 \%)$, tinggi $(68,5 \%)$, sedang $(13,0 \%)$, rendah $(1,9 \%)$ dan sangat rendah $(0 \%)$. Hasil tersebut menunjukkan bahwa Input secara keseluruhan mayoritas memberikan penilaian termasuk kategori tinggi dan sangat tinggi (85,2\%). Hal ini berarti bahwa pelaksanaan PBB di SMP Pangudi Luhur Domenico Savio Semarang dari sisi input secara keseluruhan telah dapat dilaksanakan dengan baik.

Termasuk input yaitu siswa yang merupakan anak berbakat, guru, kurikulum dan sarana prasarana. Pengertian anak berbakat dalam program percepatan belajar yang dikembangkan oleh pemerintah dibatasi pada tiga hal berikut ini (Depdiknas, 2007, p.17), (1) peserta didik yang memiliki dimensi kemampuan umum pada taraf cerdas ditetapkan skor IQ 130 ke atas dengan pengukuran menggunakan skala Wechsler, dan (2) dimensi kreativitas tinggi, dan (3) pengikatan diri (task commitment) terhadap tugas baik.

Conny Semiawan (1997, p.115) berpendapat bahwa anak berbakat dalam peri- laku intelektual, aspek teoritis, dan tingkat abstraksinya menunjukkan karakteristik mental yang berbeda dalam kecepatan melihat hubungan yang bermakna. Mereka juga tanggap mengaitkan asosiasi logis, mudah mengadaptasikan prinsip abstrak ke situasi konkret dengan mengkaji komponen situasi yang identik, serta mampu menggeneralisasikan. Menurut J. Zettel's dalam Gifted Challenge and Response For Education (Joe Khatena, 1992, p.104) menyebutkan bahwa, "Gifted Children mean children... who are endowed by nature with high intellectual capacity and who have a native capacity for high potential intellectual attainment and scholastic achievement." Dengan demikian maka diperlukan penanganan khusus agar potensi tersebut dapat berkembang maksimal.

Anak-anak berkebutuhan khusus membutuhkan layanan pendidikan khusus, termasuk yang memiliki kemampuan di bawah normal atau di atas normal. Layanan pendidikan bagi mereka yang termasuk Peserta Didik Cerdas Istimewa/ Berbakat Istimewa (PDCI/BI) adalah program percepatan belajar. Pengertian anak 
berbakat sangat luas. Kini pengertian keberbakatan selain mencakup kemampuan intelektual tinggi, juga menunjuk kepada kemampuan kreatif (Conny Semiawan, 2008, p.24).
Deskripsi data proses secara keseluruhan yang diperoleh dari 54 responden penelitian, diperolah hasil sebagai berikut:

Tabel 3. Proses PPB

\begin{tabular}{ccccc}
\hline No & Rentang Skor & Kategori & Frekuensi & Persentase \\
\hline 1 & $4,0 \leq$ Skor & Sangat Tinggi & 3 & $5,6 \%$ \\
2 & $3,3 \leq$ Skor $<4,0$ & Tinggi & 40 & $74,1 \%$ \\
3 & $2,7 \leq$ Skor $<3,3$ & Sedang & 10 & $18,5 \%$ \\
4 & $2,0 \leq$ Skor $<2,7$ & Rendah & 1 & $1,9 \%$ \\
5 & Skor $\leq 2,0$ & Sangat Rendah & 0 & $0 \%$ \\
\hline & Jumlah & & 54 & $100 \%$ \\
\hline
\end{tabular}

Sumber : hasil penelitian, diolah $2011(\mathrm{~N}=54)$

Dari Tabel 3 tersebut diketahui bahwa skor proses secara keseluruhan menunjukkan hasil sangat tinggi (5,6\%), tinggi $(74,1 \%)$, sedang $(18,5 \%)$, rendah $(1,9 \%)$ dan sangat rendah $(0 \%)$. Hasil tersebut menunjukkan bahwa Proses secara keseluruhan mayoritas memberikan penilaian termasuk kategori tinggi dan sangat tinggi $(79,7 \%)$. Hal ini berarti bahwa pelaksanaan PBB di SMP Pangudi Luhur Domenico Savio Semarang dari sisi proses secara keseluruhan telah dapat dilaksanakan dengan baik.

Proses atau process PPB SMP Pangudi Luhur Domenico Savio Semarang ditekankan kepada keterlaksanaan proses pembelajaran yang dilakukan oleh guru di kelas. Pelaksanaan pembelajaran seharihari pada PPB di SMP Pangudi Luhur Domenico Savio Semarang telah sesuai dengan rancangan penyelenggaraan $\mathrm{PPB}$ yang disusun oleh sekolah sesuai dengan kewenangan yang ditetapkan oleh pemerintah. Masalah kedisiplinan akan waktu dan ketertiban lingkungan ditekankan sebagai budaya sekolah. Meskipun demikian, sekolah tetap memberikan kesempatan yang luas kepada para guru pengampu PPB untuk menyiapkan silabus, program semester, rencana pelaksanaan pembelajaran, lembar kerja siswa, dan penilaian pembelajaran sebagai kelengkapan pembelajaran minimal.
Proses pembelajaran yang dimaksud dalam PPB yaitu akselerasi belajar. Colangelo (Reni Akbar, 2004, p.5) menyebutkan bahwa istilah akselerasi (program percepatan belajar) menunjuk pada pelayanan yang diberikan (service delivery), dan kurikulum yang disampaikan (curriculum delivery). Dalam Gifted Challence and Response For Education (Joe Khatena, 1992, p.388) menyebutkan bahwa kelas akselerasi adalah ..." as a way of spending up the growth and manifestation of intellect ini school, have provoked considerable interest, discussion, and even disagreement over the years...." Jadi kelas akselerasi adalah jalan percepatan pertumbuhan dan manifestasi intelektual di sekolah yang secara langsung berhubungan dengan anak-anak berbakat, yang menyediakan pengembangan intelektual individu.

Sebagai model layanan pendidikan, pengertian percepatan belajar termasuk juga taman kanak-kanak atau perguruan tinggi pada usia muda, meloncat kelas, dan mengikuti pelajaran tertentu pada kelas di atasnya. Sementara itu, sebagai model kurikulum, program percepatan belajar (PPB) berarti mempercepat bahan ajar dari seharusnya dikuasai oleh siswa saat itu.

Deskripsi data produk secara keseluruhan yang diperoleh dari 54 responden penelitian, diperolah hasil sebagai berikut: 
Tabel 4. Produk PPB

\begin{tabular}{ccccc}
\hline No & Rentang Skor & Kategori & Frekuensi & Persentase \\
\hline 1 & $4,0 \leq$ Skor & Sangat Tinggi & 6 & $11,1 \%$ \\
2 & $3,3 \leq$ Skor $<4,0$ & Tinggi & 34 & $63,0 \%$ \\
3 & $2,7 \leq$ Skor $<3,3$ & Sedang & 10 & $18,5 \%$ \\
4 & $2,0 \leq$ Skor $<2,7$ & Rendah & 4 & $7,4 \%$ \\
5 & Skor $\leq 2,0$ & Sangat Rendah & 0 & $0 \%$ \\
\hline \multicolumn{2}{r}{ Jumlah } & & 54 & $100 \%$ \\
\hline
\end{tabular}

Sumber : hasil penelitian, diolah $2011(\mathrm{~N}=54)$

Dari Tabel 4 tersebut diketahui bahwa skor produk secara keseluruhan menunjukkan hasil sangat tinggi $(11,1 \%)$, tinggi $(63 \%)$, sedang $(18,5 \%)$, rendah $(7,4 \%)$ dan sangat rendah $(0 \%)$. Hasil tersebut menunjukkan bahwa produk secara keseluruhan mayoritas memberikan penilaian termasuk kategori tinggi dan sangat tinggi $(74,1 \%)$. Hal ini berarti bahwa pelaksanaan PBB di SMP Pangudi Luhur Domenico Savio Semarang dari sisi produk secara keseluruhan telah dapat dikatakan baik.

Produk pendidikan tidak cukup hanya dilihat dari aspek akademik, tetapi juga aspek nonakademik. Aspek nonakademik tidak bisa hanya dilihat dari berbagai kejuaraan atau lomba yang dimenangi siswa, tetapi juga harus dilihat dari aspek perkembangan kedewasaan. Terkait dengan hal ini, hasil penelitian mengungkapkan fakta bahwa siswa reguler lebih dewasa dilihat dari rasa tanggung jawab dan kematangan emosi. Dapat dikatakan bahwa pembelajaran di kelas akselerasi lebih menekankan pada aspek akademik, namun kurang menumbuhkembangkan sikap mental peserta didik.

\section{Simpulan dan Saran}

Simpulan

Persepsi terhadap konteks (Context) meliputi indikator: (a) dukungan pemerintah, (b) dukungan masyarakat, (c) dukungan pihak yayasan, dan (d) komitmen pengelola telah menunjukkan hasil sangat tinggi 23,3\%, tinggi 39,5\% (jumlah nilai kategori tinggi dan sangat tinggi, $62,8 \%$ ). Skor tertinggi pada indikator komitmen pengelola dan terendah pada dukungan pemerintah.

Persepsi terhadap input (Input) meliputi indikator : (a) karateristik siswa, (b) karakteristik guru, (c) karekteristik kurikulum dan (d) ketersediaan sarana prasarana pendidikan menunjukkan hasil sangat tinggi 16,7\% dan tinggi 68,5\% (jumlah nilai kategori tinggi dan sangat tinggi, $85,2 \%$ ). Hal ini berarti bahwa pelaksanaan PBB dari sisi input secara keseluruhan telah dapat dilaksanakan dengan baik. Namun masih ada guru akselerasi yang direkrut tidak melalui seleksi dan tidak melalui pelatihan terlebih dulu. Semua guru menyatakan bahwa mereka telah menggunakan strategi mengajar yang menarik dan mudah dimengerti siswa, tetapi hanya $7,04 \%$ siswa yang menyatakan setuju, 28,57\% netral, dan sisanya 64,29\% tidak setuju. Sebanyak $50 \%$ siswa menyatakan guru tidak menguasai materi pelajaran.

Persepsi terhadap proses (Process) meliputi indikator : (a) administrasi KBM dan (b) kegiatan belajar mengajar (KBM) menunjukkan hasil kategori sangat tinggi $5,6 \%$ dan tinggi $74,1 \%$ (jumlah nilai kategori tinggi dan sangat tinggi, 79,7\%). Hal ini berarti bahwa pelaksanaan PPB di SMP Pangudi Luhur Domenico Savio Semarang dari sisi proses secara keseluruhan telah dapat dilaksanakan dengan baik. Skor evalusi pada indikator kegiatan belajar mengajar lebih tinggi dibanding pada indikator administrasi KBM. 
Persepsi terhadap produk (Product) meliputi indikator : (a) ujian/test formatif, (b) ujian/test semester, (c) ujian nasional dan (d) prestasi kegiatan ekstrakurikuler menunjukkan hasil dengan kategori sangat tinggi $11,1 \%$ dan tinggi $63 \%$ (jumlah nilai kategori tinggi dan sangat tinggi, 74,1\%). Hal ini berarti bahwa pelaksanaan PBB dari sisi produk secara keseluruhan telah dapat dikatakan baik. Skor tertinggi pada hasil ujian nasional dan skor terendah pada evaluasi prestasi kegiatan ekstrakurikuler. Dilihat dari aspek nonakademik lainnya yaitu dari sisi tanggung jawab dan kestabilan emosi, siswa-siswa kelas akselerasi lebih rendah dibandingkan siswa-siswa regular.

Saran

Peningkatan kualitas SDM, khususnya guru-guru, pengelola PPB merupakan salah satu faktor penentu keberhasilan program. Oleh karena itu, pengembangan kompetensi guru dalam hal penguasaan metodologi, pengembangan kurikulum melalui pelatihan atau workshop rutin dan berkelanjutan perlu dibuda-yakan sebagai salah satu prioritas.

Penempatan siswa pandai dan ber-

bakat tetapi memiliki kekurangan dari segi finansial hendaknya diakomodir dalam kelas PPB dengan pemberian beasiswa atau dengan pemberian keringanan biaya.

Kegiatan sekolah nonakademik khususnya kegiatan ekstrakurikuler dalam berbagai jenis kegiatan bagi siswa peserta Program Percepatan Belajar hen- daknya tetap berjalan agar siswa berkembang secara utuh.

Pencatatan administrasi kegiatan belajar mengajar di kelas yang oleh sebagian guru sering dilupakan hendaknya tidak diabaikan pada kelas PPB karena itu merupakan bukti legal formal yang penting untuk tertib administrasi dan dokumentasi sekolah.

\section{Daftar Pustaka}

Conny Semiawan. (2008). Perspektif pendidikan anak berbakat. Jakarta: Gramedia.

Depdiknas.(2007). Pedoman penyelenggaraan pendidikan untuk peserta didik berkecerdasan istimewa. Departemen Pendidikan nasional, Direktorat Jenderal Manajemen Pendidikan Dasar dan Menengah Direktorat Pembinaan Pendidikan Luar Biasa.

Huberman dan Miles (1992) Qualitative data analysis. An Expanded sourcebook. London: Sage Publication Ltd.

Khatena, J. (1992). Gifted; challenge and response for education. Illinois: F.E Peacock Publishers, Inc.

Mulyana, Dedy (2000). Ilmu komunikasi suatu pengantar. Bandung: PT Remaja Rosda Karya

Reni Akbar. (2004). Akselerasi. Jakarta: Grasindo

Thoha, Miftah, (2000). Perilaku organisasi, konsep dasar dan aplikasinya. Jakarta: Raja Grafindo Persada. 